\title{
Design and Implementation of Digital Art Teaching System Based on Interactive Virtual Technology
}

\author{
https://doi.org/10.3991/ijet.v11i11.6254 \\ You-tian Ye \\ Hubei Institute of Fine Arts, Hubei, China
}

\begin{abstract}
Aiming at design a digital art teaching system and improve its performance, the interactive virtual technology is proposed. The art design major education innovation must abide by the open character and build scientists' teaching and curricula system and quality judgment criteria and mechanisms. We can exploit digital art major education with creativity, so invigorated digital art design stimulates education develops soundly, orderly and creatively. The system was implemented in 9 levels of the 206 universities. The results indicate that the system will help the combination of science and art, highlight distinctive university management with scientific teaching system and transform students 9 intelligence cultivation into wisdom and creation.
\end{abstract}

Index Terms - digital art teaching system, interactive virtual technology, design and implementation

\section{INTRODUCTION}

Digital art learning management system is based on the increase in digital art professional development and employment needs while growing up. Art and design talent will be growing demand; digital art learning management system based on interactive virtual technology helps to better train digital art talent. Digital art information technology and the perfect combination of art, fully demonstrated the expressive arts. At present, domestic and foreign research and application of digital art education system does not reach the potential expected in the current situation and effects, there is a great development.

Through the existing process reengineering, the introduction of digital art learning management system based on interactive virtual technology, and can do a lot of work through the system. In functional analysis, including user information management, independent learning management, management, teaching quality management and platform management five functional modules, The user information management module mainly includes parameters setting, teacher registration, face basic data and student information registration, students learning management mainly includes online learning, online learning, online testing, information exchange, resource download, and teaching management, including online teaching, online teaching, test, teaching, training, virtual, questionnaire, etc.

Due to the poor interaction of traditional art teaching method, the efficiency of the usage of art teaching resources is low. In order to solve the problem, interactive visual thinking should be used to reform the traditional art teaching method.
Because of interactive virtual roaming in simulation scene based on virtual reality technology, has characteristics of multi-sensory, interactive, immersive and autonomy etc., it is widely used in structure exhibition, personnel operation training, product structure design verification.

This paper mainly studies the application of the interactive simulation technology in art teaching from five parts. The first section is the preface which introduces the study purpose, background, content and methods of this paper. The second section is the overview part. It summarizes the related researches of the interactive simulation construction in Art teaching, both at home and abroad. The third section is an important part of this article which dissects the necessity and viability to establish an interactive simulation in the Art teaching. It reveals the interdependence and promoting relationships between the interactive simulation technologies in the Art teaching. It introduces the basic algorithm in the Art teaching. The fourth section makes a detailed mode of the interactive simulation technology in the Art teaching. The experiment is done in this part. The fifth section discusses the comparison result and data obtained in the fourth part.

\section{OVERVIEW}

With the development of computer technology, virtual reality technology is becoming related to other disciplines increasingly, and the research of virtual reality technology in teaching model has been being the focus. Interactive virtual teaching system is based on information technology, networked virtual environment which integrates all kinds of development tools and technique. It has good prospects and development potential, and virtual interactive studies indicate the direction of virtual reality. With the development of virtual reality technology and system simulation, process simulation system and 2D interactive virtual system cannot satisfy the user pursuit of immersion and interaction on simulation software, so the highinteractive, 3D immersed interactive virtual system has become a hot topic. Virtual Reality is a new type of multimodal human-computer interaction mode. People can feel the Virtual simulated by computer in various ways based on this mode. The developed of Virtual Reality is an interdisciplinary based on computer graphics, computer simulation technique, human-computer interaction technique, multimedia technology and sense technology[1-3]. Now, virtual reality technology, multimedia technology and network technique have the best prospect. Virtual lab is a new mode based on virtual reality technology. Users can finish the experiment under it just as they did in reali- 
ty lab, ever more, they may get better learning effect through it. Now the developed of virtual lab cover many fields, such as physics, chemistry, medical science, military, machinery. And there are more and more tools and methods to develop virtual lab. There are many tools can be used to design the virtual lab, including threedimensional and two-dimensional tools, and they all have their own strong point, so we should develop a new way to integrate the advantage of three-dimensional and twodimensional.

With the abroad application of computer and network technology, the Internet develops rapidly, and ultra-media environment is maturing. Digital art learning management system based on interactive virtual technology is created by digital methods and concepts, so how to integrate teaching resources in this existing network to build digital art will have a direct impact on digital art courses teaching quality, which core is digital content creation. At the same time, along with the rise of digital art, At the same time, along with the rise of digital art, social needs of the digital talent is very urgent, to train high-quality digital personnel become very concerned about the issue.

Therefore, in order to explore digital art teaching and training of personnel to better serve the university curriculum innovation in digital art education, it provides a digital art teaching mode based on interactive virtual technology and learning approach under network environment digital art teaching information management system is designed and developed to explore an Internet-based open learning mode. Detailed introduction.NET interactive system is proposed in the framework of some important technologies and key content.

The characteristics of digital art design major determine that we must combine science and art, technology and design, sciences and humanities. Therefore, on the discipline knowledge structure, it puts emphasis on rational, scientific, artistic and humanistic features. What's more, it's guided by interdisciplinary, compatibility and permeability. Otherwise, it breaks the balance and can build scientific discipline structure.

A brief description of the main technology of NET puts forward the background and function of NET, the important language C\# and ASP. NET was discussed in detail, then in-depth analysis and comparison of technology in .NET, finally analyzes all kinds of role and function of the database management system, and analyzes and illuminates the SQL Server 2005 system. The management system through in-depth study of.NET framework and based on the combination mode, teaching information interactive system based on virtual technology to lay the foundation, to achieve a good target. In this paper a flexible multi-alternate distributed interactive virtual reality system framework based on OGRE is introduced to solve the cooperative controlling of scene rendering. By importing the cooperative alternation technique, the control platform, the web server platform and the render platform are designed and the distributed cooperative rendering method based on OGRE is proposed. The real-time synchronization of multi-render nodes controlled by one control node and multi-control nodes in one scene is realized. The NET technology, database technology and the $\mathrm{C}$ \# language and other advanced development tools are researched and discussed deeply, and based on these jobs, the system is completed the designed. This system is basically realized the digital arts courses related to teaching management and remote access capabilities, which defines the teaching core of teachers, and so it enhance the teaching effectiveness.

Introduce the seven modules, the system includes: the design of user management, teacher information management, course management, course management, performance management, information management, teaching interaction management module. The design and the design of each module separately include three to four sub modules. In the system database design, fully in accordance with the principles of database design and sequence to complete, mainly needs analysis first, and then convert the E-R diagram, finally in the conversion for the data model, the final formation of database. Lay the foundation for the design for the design and the implementation. The framework of the system is shown in the following figure 1 and the kernel for the system is shown in the figure 2 .

It's the invisible force and endowed with digital art design's connotation. Talents that digital art design major education cultivates mainly create material and spiritual products. So the design of any product not only needs digital art design expressive ability and skill, but also needs the support of the humanities' support. That is because it involves the humanities such as philosophy, history, literature, economy, religion, ethics, folklore, market study, aesthetics, ethnics and etc. If you don't know, or do not study it, the products you design cannot be popular with society, market and customers or cultivate people's taste, thus lose the charm of the digital art design [4-5].

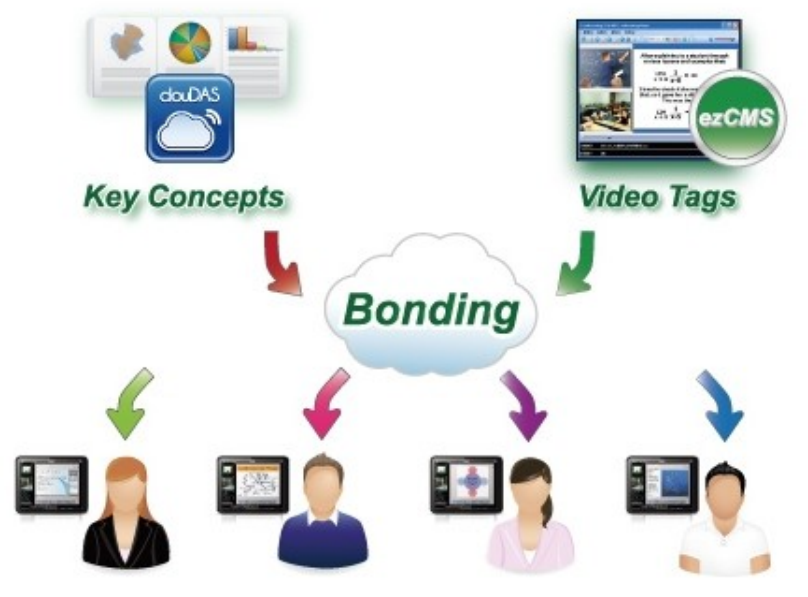

Figure 1. The framework of the system

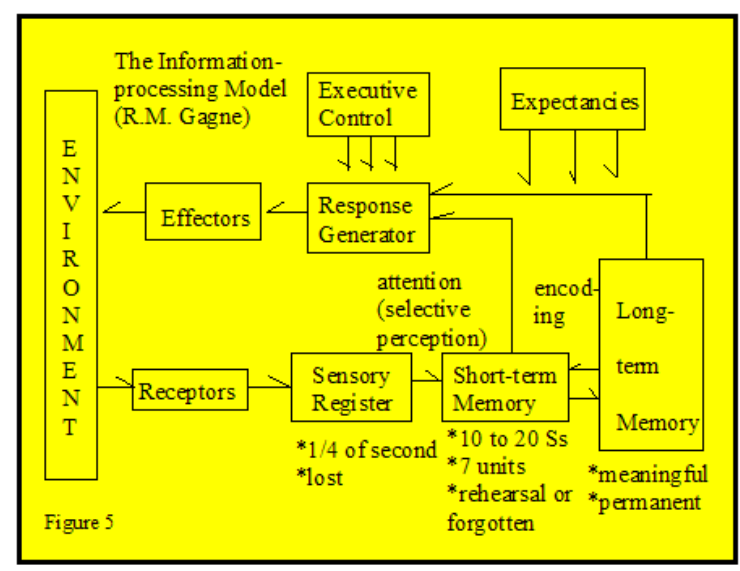

Figure 2. The kernel of the system 


\section{METHOD AND ALGORITHM}

Digital art design major enables integration and communication of science and art, which makes them become complementary. The complementarity not only exalts the advantages of science and art but also covers the shortages. Scientific logical thinking makes people sensible which constitute the order while arts imagine thinking makes people sensitive and makes world become art's maze. Scientific speed, strength and depth truth can build platform and create imaginable miracle, e.g. powerful computer and software can create different virtual situations and images. However, art's imagination and association with its unbeatable skills and wisdom shape the beautiful artistic image. Any free, elegant, romantic, reserved and humorous images can lead people to endless aftertaste. Teaching system and approaches guarantee digital art design major education. Scientific and rational teaching system is important in teaching innovation. What is more, artistic teaching method has an important effect on teaching system.

System and scientific character means exact, sensible, effective and distinctive teaching system. There exist isolated parts which combine to produce different levels, thus interweave to an organic whole. To judge and weigh the system's standard needs to be effective. The powerful system needs operational mechanism to regulate and control, for it involves two aspects: static and dynamic state. Without good operational mechanism, system's superiority can't be brought into full play. Moreover, because of teaching systems different subjective and objective factors, it has vivid individuality [6]. The figure 3 shows the teaching classroom based on the interactive visual technology.

Comprehension means that it9s a whole externally and complicated internally. To different internal organization and elements, we need to combine them if we want to bring them into full play. To some degree, comprehension is integration. We need to give full play to advantage in resources, i.e. realize courses, comprehension of practical teaching, humanity of teaching and learning by allocating financial and human resources.

Teaching system needs to be in order. Or system may be in the dangerous state. Order needs to conform to regular rule and embodies art truth. Good teaching order guarantees teaching quality which can create and form good learning atmosphere. The sequence of the class is the need of knowledge points' cohesion which embodies the prin-

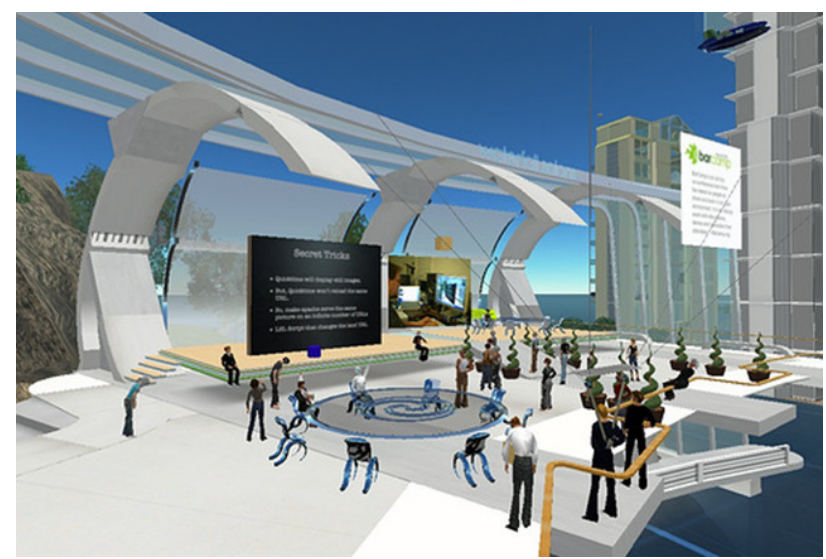

Figure 3. The teaching classroom based on the interactive visual technology ciples of progressing step by step, being interspersed with each other and organic integration. In that way, students can understand, digest and absorb knowledge better.

The basic algorithm is shown in the following equations:

$$
\hat{F}=\hat{W}^{T} \Phi(\mu)
$$

It's provided by the adaptive weight law. So estimation error of the weight is

$$
\tilde{W}=W-\hat{W}
$$

The positive values $\mathrm{W}_{\max }$ as follows:

$$
\|W\|_{F} \leq W_{\max }
$$

The adaptive weights law is defined as

$$
\begin{array}{r}
\dot{\hat{W}}=-k G\left\|z_{2}\right\| \hat{W}-z_{2}^{T} G \Phi(\mu) \\
\varphi_{j i}\left(\mu_{j}\right)=\exp \left(\frac{-\left(\mu_{j}-C_{j i}\right)^{2}}{b_{j i}{ }^{2}}\right), \text { for } i=1,2, \mathrm{~K}, H
\end{array}
$$

In this space, the $\mathrm{m}^{\text {th }}$ multidimensional receptive-field function is defined as

$$
\Phi_{m}(\mu)=\prod_{j=1}^{L} \varphi_{j i}\left(\mu_{j}\right), \text { for } m=1,2, \mathrm{~K}, N
$$

The function can be written in a vector notation as

$$
\Phi(\mu, C, b)=\left[\Phi_{1}, \Phi_{m} \ldots, \Phi_{N}\right]^{T}
$$

The weight memory space with $\mathrm{N}$ components can be expressed in a vector as

$$
W=\left[W_{1}, W_{m}, \ldots, W_{N}\right]^{T}
$$

The activated weights in weight memory space, which can be written in a vector form as

$$
y=W^{T} \Phi(\mu)(9)
$$

The state variables and the desired values can be defined as follows:

$$
z_{1}=x_{1}-y_{d}
$$

and

$$
z_{2}=x_{2}-\alpha_{1}
$$

The following tracking error dynamics is shown as:

$$
\dot{z}_{1}=\dot{x}_{1}-\dot{y}_{d}=x_{2}-\dot{y}_{d}=z_{2}+\alpha_{1}-\dot{y}_{d}
$$

From (2) and (6), it can be obtained:

$$
\dot{z}_{2}=\dot{x}_{2}-\dot{\alpha}_{1}=-M^{-1} C x_{2}-M^{-1}\left(G_{g}+d\right)+M^{-1} \tau-\dot{\alpha}_{1}
$$

$\tau$ is selected as

$$
\tau=-\lambda_{2} z_{2}-z_{1}-F
$$

Then we can get:

$$
V_{2}=V_{1}+\frac{1}{2} z_{2}^{T} M z_{2}
$$$$
\dot{V}_{2}=-\lambda_{1} z_{1}^{T} z_{1}-\lambda_{2} z_{2}^{T} z_{2}+z_{2}^{T}(f-F)-z_{2}^{T}\left(G_{g}+d\right)
$$

The ideal weight $\mathrm{W}$ from (10) and expressed as

$$
F=W^{T} \Phi(\mu)
$$


It plays an important role in education quality and the major education innovation. Teaching approaches are the integration of style and methodology which are in close relationship with teachers' comprehensive ability and quality. They are incorporated the knowledgeable, academic and artistic character into a whole. Therefore, teaching is an art which can be divided into superior, average and inferior class. In the process of expressing artistic teaching language, students' reception depends directly on teaching artistic level [7].

It's the mental hint and activity based on motivating students' learning emotion. It needs the teacher to expound the knowledge points clearly and in simple language. What's more, the teacher needs to grasp the main points. In the process of knowledge-transference, the teacher and students need to have a close rapport, or the questions teacher puts forward can't be answered by the students, thus the atmosphere becomes embarrassed. Therefore, on the discipline knowledge structure, it puts emphasis on rational, scientific, artistic and humanistic features. The system module is shown in the figure 8 .

From the model and the algorithm discussed above, we can develop a whole system for art teaching system based on the interactive visual technology. Taking the art design major as an example. Assume that the virtual scene is the exhibition hall. The student is the designer of the exhibition hall. First, the student is assumed to design the exhibition hall layout and internal channel which is shown in the following figure 4 and 5 . Then the exhibits are designed by the students.

Using interactive virtual technology, we will link up layout, channel and exhibits to form a virtual exhibition hall. Using the virtual interactive technology, we are equipped with virtual tour guide which is shown in the figure 7 and virtual display which is shown in the figure 7 , to form a complete exhibition hall design case. The designers are put in the visual exhibition hall. The entire process allows the designer experience the whole process from entering the exhibition hall to enjoy the exhibits in an interactive way.

\section{EXPERIMENT RESULT}

Integrated innovation is the absorption and application of human beings' advanced cultural fruits. By drawing on educational ideology, modes, approaches and system from home and abroad, we can form our own new mode of talents development. Because the new mode can't be copied, fit for our university's reality and gives full play to the energy of the mode, it can cultivate talents who can adapt to the need of cultural innovative and other economic industries. Especially after students enter the society, their potential can be brought into full play and they can become creative and valuable top talents. Thus, it can prove the success of the new mode of talents development. This judge is persuasive, influential, and attractive and shock in the society [8-11].

We need to make students become the creators of wisdom, not the machine of rote learning. It is proved that the person who has fundamental knowledge means his intelligence, but we need to develop if intelligence transformed into wisdom. The key to develop intelligence is to train and educate creative thought and ability which need to be accumulated and develop from low to high. Moreover, non-intellectual qualities play an important role in

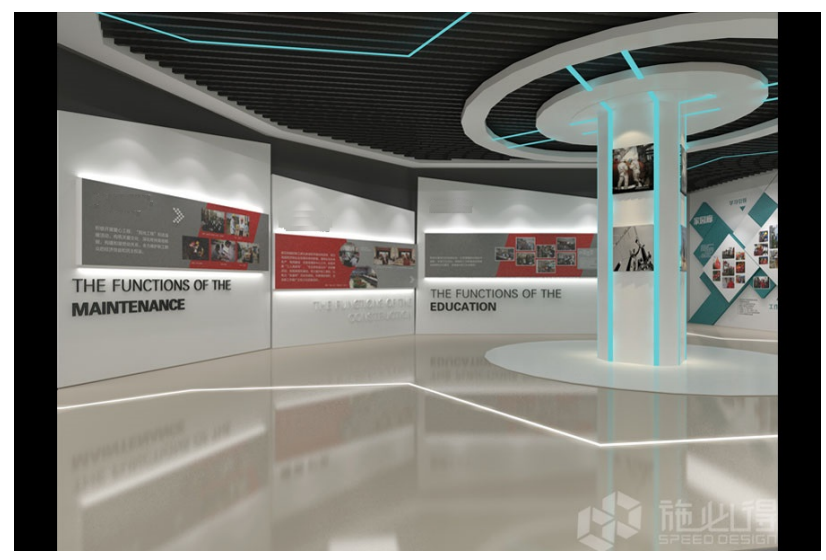

Figure 4. The exhibition hall layout

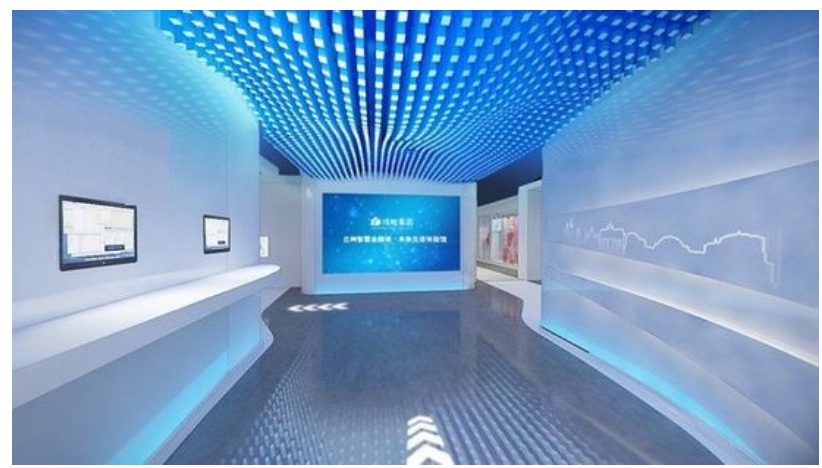

Figure 5. The exhibition hall internal channel

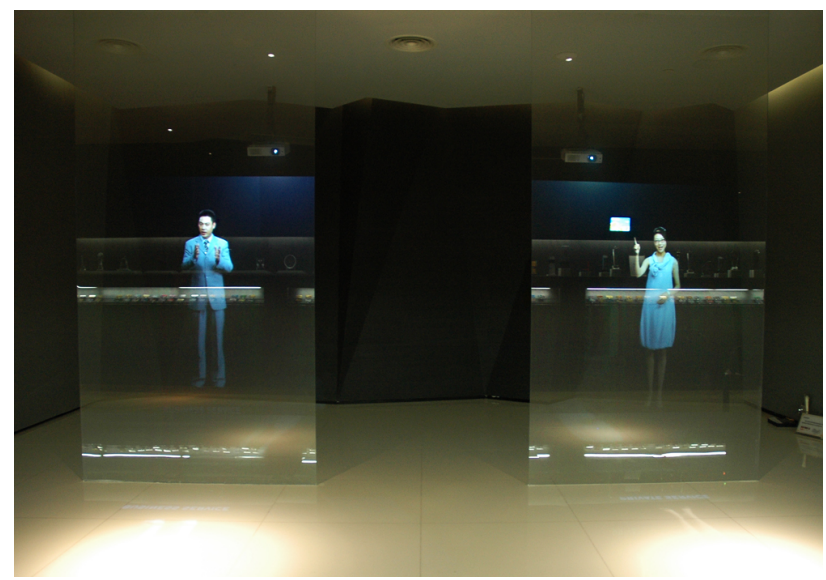

Figure 6. The virtual tour guide in exhibition hall

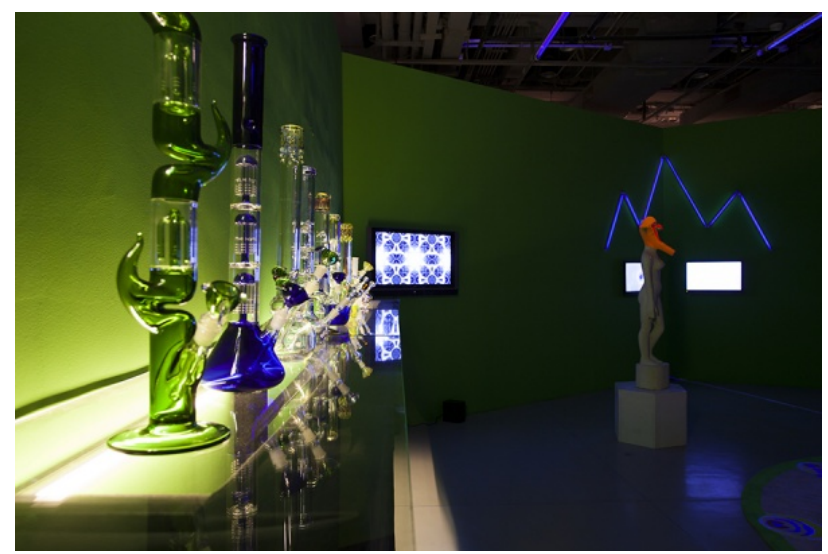

Figure 7. The visual scene of the design of exhibitions display 
improving and perfecting intelligence. Only by combining intellectual and non-intellectual qualities, creation can be sparked.

It is closely related with talents development and teaching Objective. Whether curricula system is perfect or not influences students, knowledge structure. It requires that courses design should take function and purpose of different courses into consideration scientifically and rationally, i.e. incorporate all the curricula resources in order to achieve the best effect by effective operation. Basically speaking, we need to control the proportion of different curricula to avoid disorder or the problem of neglecting the essentials.

We need to study the theory and practice of advanced talents 9 cultivation mode. How to design and control condition and atmosphere of its success? We can absorb the advanced experience by studying in-depth nature and its connotation and denotation. We can build the new mode of talents development according to our university's reality. We cannot copy others, or desired result can't be reached.

In conclusion, the problems that digital art design major involves are complicated. Because from the perspective of educational history, the history of this major from home and abroad is not long. Because the major is emerging, the experiences we can draw on are confined. The study of this major education lacks system. Therefore, the major education innovation must abide by the open character; build scientists' teaching and curricula system and quality judgment criteria and mechanisms. We can exploit digital art major education with creativity, so invigorated digital art design stimulates education develops soundly, orderly and creatively. There are 9 levels of the 206 universities, and the result of the sub-items was as followed Table 1.

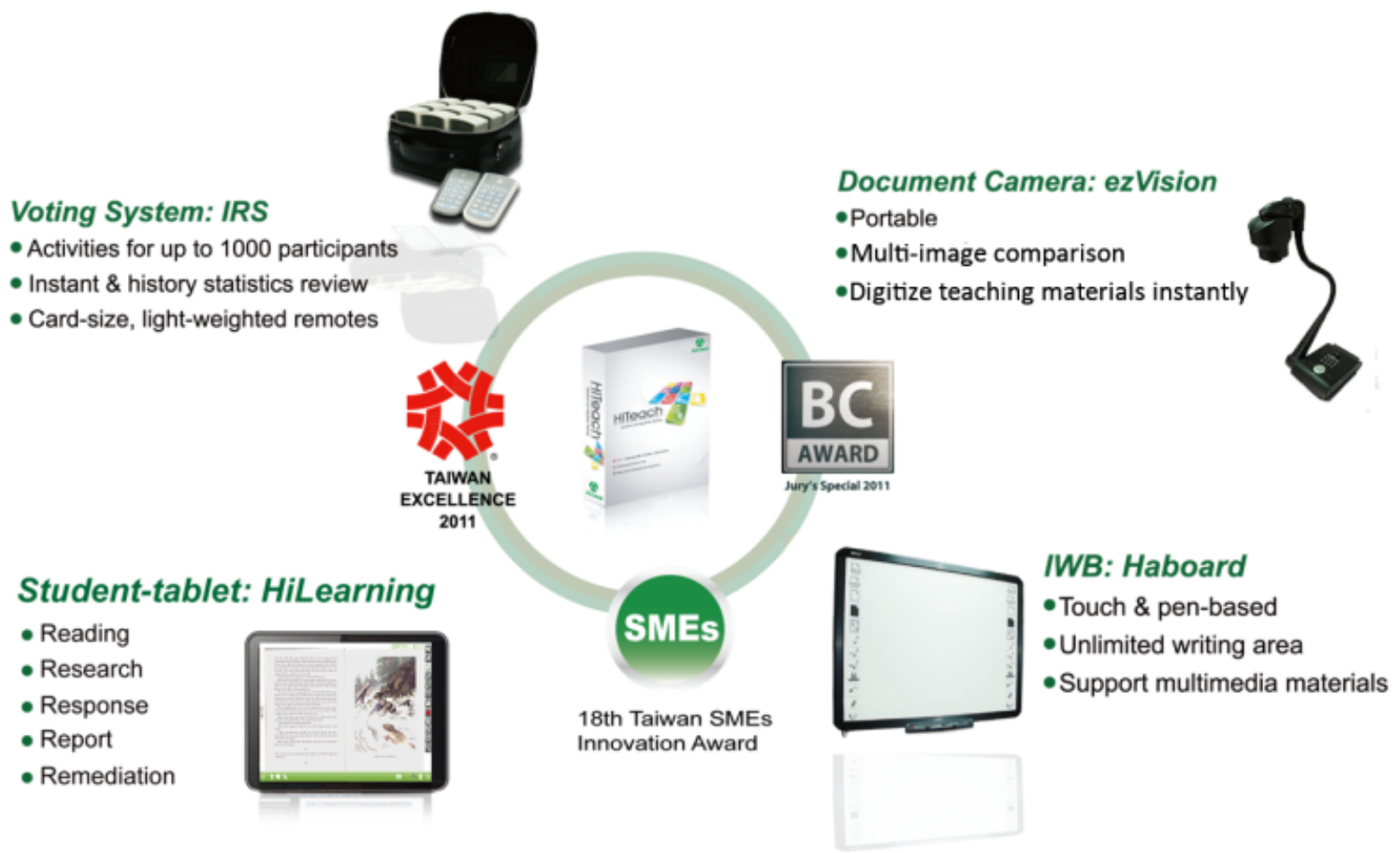

Figure 8 . The system module

TABLE I.

THE 9 LEVELS OF SUB-ITEMS

\begin{tabular}{|c|c|c|c|c|c|c|c|c|c|}
\hline \multicolumn{1}{|c|}{ Type of the university } & \multicolumn{9}{|c|}{ No. of the sub-items } \\
\hline \hline category & 1 & 2 & 3 & 4 & 5 & 6 & 7 & 8 & Total \\
\hline 1st level & 0.94 & 0.91 & 0.78 & 0.98 & 0.91 & 0.88 & 0.88 & 0.63 & 0.84 \\
\hline 2nd level & 0.84 & 0.78 & 0.66 & 0.90 & 0.74 & 0.85 & 0.75 & 0.62 & 0.74 \\
\hline 3rd level & 0.86 & 0.81 & 0.68 & 0.92 & 0.77 & 0.84 & 0.75 & 0.50 & 0.73 \\
\hline 4th level & 0.81 & 0.75 & 0.61 & 0.89 & 0.70 & 0.82 & 0.70 & 0.41 & 0.67 \\
\hline 5th level & 0.78 & 0.72 & 0.60 & 0.83 & 0.67 & 0.73 & 0.65 & 0.53 & 0.66 \\
\hline 6th level & 0.76 & 0.68 & 0.57 & 0.82 & 0.62 & 0.76 & 0.60 & 0.38 & 0.62 \\
\hline 7th level & 0.71 & 0.64 & 0.53 & 0.75 & 0.58 & 0.71 & 0.57 & 0.47 & 0.59 \\
\hline 8th level & 0.65 & 0.58 & 0.49 & 0.68 & 0.50 & 0.62 & 0.47 & 0.37 & 0.52 \\
\hline 9th level & 0.57 & 0.50 & 0.43 & 0.57 & 0.39 & 0.50 & 0.36 & 0.28 & 0.44 \\
\hline
\end{tabular}




\section{DISCUSSION}

From the experiment above, we may conclude that be particular about art teaching artistically should be ideal art teaching surely, be appropriate to be ideal most as for art teaching. Being appropriate implies that art teaching should be aesthetically and significantly for a student from content, form, method etc. As a result, appreciation of the beauty all the time of the teaching course may be one kind of very advanced teaching art to other disciplines, but to the discipline of art teaching is one kind of necessary and fundamental request. Otherwise there is no way to realize the aim of appreciation of the beauty and educating people. But for art teaching which teaching artistically needed most, the theoretic study about the artistically teaching is not satisfied. Theory and practice always are effected and promoted mutually theory originates from practice, the lag of theory will lead to lag of practice directly, the lag of practice makes the theory get in further difficult position. Without investigation and discussion about art nature of art teaching, without the description to art teaching art appreciation of the beauty particularity, without the rational thinking to art appreciation of the beauty dimension about art teaching, without discovering a problem and extracting elite from the teaching course, there would be no way to urge the art teacher to scan and create their own artistic teaching methods consciously. As a result the main body of a system have been attempting to carry out investigation and discussion on above-mentioned problem, an entire theory system of art teaching may be not calculating, but the efforts would be achieved on putting the theory and practice developing towards the benign direction all the time, promoting the art teaching to a finer condition ceaselessly.

\section{CONCLUSION}

Against the background of knowledge-based economy and explosive information age, the big problem of digital art design major construction is how to be in line with international education and cultivate creative, applicationoriented talents of well-round abilities in the vision of multicultural. Aiming at design a digital art teaching system and improve its performance, the interactive virtual technology is proposed in this paper. This paper elaborates the important role that digital art design major plays in industrial economics and puts forward that the major's development lies in innovation by researching. The art design major education innovation must abide by the open character and build scientists' teaching and curricula system and quality judgment criteria and mechanisms. On the profound level, we need to be guided by interdisciplinary, combine science with art, highlight distinctive university management with scientific teaching system and transform students 9 intelligence cultivation into wisdom and creation. All in all, we need to build the new mode of digital art design talents cultivation. We can exploit digital art major education with creativity, so invigorated digital art design stimulates education develops soundly, orderly and creatively.

\section{REFERENCES}

[1] H. Jing, "The Study on the Impact of Data Storage from Accounting Information Processing Procedure," International Journal of Database Theory and Application, vol. 8, no.3, pp. 323-332, June 2015. https://doi.org/10.14257/ijdta.2015.8.3.28

[2] Y. Zhou, "Application of Automatic Choreography Software Based on Virtual Technology in the Gymnastics Teaching," International Journal of Emerging Technologies in Learning, vol. 11, no.5, pp. 39-44, May 2016. https://doi.org/10.3991/ ijet.v11i05.5692

[3] H. Jing, "Node deployment algorithm based on perception model of wireless sensor network," International Journal of Automation Technology,vol.9, no.3, pp. 210-215, April 2015. https://doi.org/10.20965/ijat.2015.p0210

[4] C. Ji, and M. Fan, "The application of web data mining in personalized modern distance education," Energy Procedia, no.13, pp.714-720, 2011.

[5] Y. Li, J. Sun, and W. Qiang, "Application of Data Mining in Personalized Remote Distance Education Web System," Open Cybernetics \& Systemics Journal, vol. 9, no.1, pp. 1769-1775, 2015. https://doi.org/10.2174/1874110X01509011769

[6] P. Li, "Based on Data Mining Technology in Distance Education System Applied Research," Applied Mechanics \& Materials, pp.2260-2264, 2014.

[7] Y. Gandole, "Computer Modeling and Simulation of Ultrasonic System for Material Characterization," Modeling and Numerical Simulation of Material Science, vol. 1, no. 1, pp. 1-13, 2011. https://doi.org/10.4236/mnsms.2011.11001

[8] J. Xu, L. Chen, W. Gao, et al., "CBTC Simulation Platform Design and Study," Journal of Computer and Communications, vol. 7, pp. 61-67, 2015. https://doi.org/10.4236/jcc.2015.39007

[9] J. Yang, M. Fan, G. Wang, et al., "Simulation Study Based on Somewhat Homomorphic Encryption," Journal of Computer and Communications, vol. 7, pp. 109-111, 2014. https://doi.org/10.4236/jcc.2014.22019

[10] Y. Wang, W. Zhu, H. Gen, et al., "Multi-Agent Based Social Integrity Simulation and Its Evolution," Sociology Mind, vol. 7, pp. 302-305, 2012. https://doi.org/10.4236/sm.2012.23040

[11] X. Wang, J.W. Wang, Y.F. Zhong, et al., "Research of data mining technology application in personalized distance education platform," Journal of Heilongjiang Institute of Technology, 2010.

\section{AUTHOR}

You-tian Ye is with Hubei Institute of Fine Arts, Hubei, China(623990813@qq.com).

The paper is supported by: 2015 annual provincial Department of Education Science and technology research project(No. D20152301): Study on digital communication and application of filial piety culture image and 2013 educational science planning and research project in Hubei Province(No.2013B134): Research on teaching and writing practice of experimental animation in the perspective of cross media. Submitted 09 September 2016. Published as resubmitted by the author 03 November 2016. 